\title{
Workplace learning from a socio-cultural perspective: creating developmental space during the general practice clerkship
}

\author{
J. van der Zwet $\cdot$ P. J. Zwietering $\cdot$ P. W. Teunissen • \\ C. P. M. van der Vleuten - A. J. J. A. Scherpbier
}

Received: 15 October 2010/ Accepted: 13 December 2010/Published online: 28 December 2010

(C) The Author(s) 2010. This article is published with open access at Springerlink.com

\begin{abstract}
Workplace learning in undergraduate medical education has predominantly been studied from a cognitive perspective, despite its complex contextual characteristics, which influence medical students' learning experiences in such a way that explanation in terms of knowledge, skills, attitudes and single determinants of instructiveness is unlikely to suffice. There is also a paucity of research which, from a perspective other than the cognitive or descriptive one, investigates student learning in general practice settings, which are often characterised as powerful learning environments. In this study we took a socio-cultural perspective to clarify how students learn during a general practice clerkship and to construct a conceptual framework that captures this type of learning. Our analysis of group interviews with 44 fifth-year undergraduate medical students about their learning experiences in general practice showed that students needed developmental space to be able to learn and develop their professional identity. This space results from the intertwinement of workplace context, personal and professional interactions and emotions such as feeling respected and self-confident. These forces framed students' participation in patient consultations, conversations with supervisors about consultations and students' observation of supervisors, thereby determining the opportunities afforded to students to
\end{abstract}

J. van der Zwet $(\varangle)$. P. W. Teunissen - C. P. M. van der Vleuten

Department of Educational Development and Research, Faculty of Health, Medicine, and Life Sciences, Maastricht University, PO Box 616, 6200 MD Maastricht, The Netherlands e-mail: j.vanderzwet@educ.unimaas.nl

P. J. Zwietering

Department of General Practice, Faculty of Health, Medicine, and Life Sciences,

Maastricht University, Maastricht, The Netherlands

P. J. Zwietering

The Netherlands Health Care Inspectorate, 's Hertogenbosch, The Netherlands

\author{
A. J. J. A. Scherpbier \\ Institute for Medical Education, Faculty of Health, Medicine, and Life Sciences, Maastricht University, \\ Maastricht, The Netherlands \\ P. W. Teunissen \\ Department of Obstetrics and Gynaecology, VUmc Medical Centre, Amsterdam, The Netherlands
}


mind their learning. These findings resonate with other conceptual frameworks and learning theories. In order to refine our interpretation, we recommend that further research from a socio-cultural perspective should also explore other aspects of workplace learning in medical education.

Keywords Qualitative research · Workplace learning - Undergraduate medical education . Clerkship $\cdot$ General practice $\cdot$ Learning perspectives $\cdot$ Socio-cultural perspective

\section{Introduction}

Primary health care settings, including general practice, have been characterised as powerful workplaces for teaching and learning in undergraduate medical education (Gordon et al. 2000; Pearson and McKinley 2010; Dornan et al. 2006; Murray et al. 1999). Educational research in this setting is predominantly descriptive and has resulted in valuable information about students' learning experiences. Studies have revealed for example that in general practice settings students specifically learn about aspects of medicine like chronic and minor illnesses, communication skills and dealing with uncertainty, whereas hospital settings are typically the workplace where students learn about acute illnesses and diagnostic procedures (O'Sullivan et al. 2000; Svenberg 2007). The stronger emphasis on communication skills in general practice appears to be due to students seeing '.. patients in a zone of transition between society and healthcare' (Svenberg 2007). Experiences in general practice confront students with patient perspectives, raise their awareness of psychosocial issues regarding health and disease and help them to value and practise a patient-centred approach (O'Sullivan et al. 2000; Svenberg 2007; Thistlethwaite and Jordan 1999). In this way students also learn to develop their individual consultation style (Svenberg 2007).

Research has underlined the importance of the role of the supervisor in general practice learning. In an earlier study we found that perceived instructional quality of general clerkships was determined most strongly by the quality of supervision (van der Zwet et al. 2010), while O'Sullivan et al. (2000) reported an increase in feelings of competence and confidence as a result of a high level of one-to-one supervision and feedback (O'Sullivan et al. 2000). Similar findings resulted from another study in which students labelled good community attachments as "a good general practitioner (GP)", which covered not only the GP as a role model and teacher but also the general quality of the learning environment (Silverstone et al. 2001). General practice placements tend to be characterised by a oneto-one relationship with the supervisor and a generally informal personal approach. As a result, students feel at ease and less pressured to impress teachers and conceal weaknesses. As a result they are not afraid to ask questions, which benefits their learning experiences (O'Sullivan et al. 2000; Thistlethwaite and Jordan 1999). Two studies which used students' learning experiences to identify general concepts of (enhancement of) teaching and learning processes in a general practice setting (Epstein et al. 1998; Fernald et al. 2001), also underlined the importance of the role of the supervisor and of active and collaborative teaching and learning based on a trusting relationship.

The research findings summarised above describe what students learn in general practice and what contributes to their learning process. These studies generally depart from a cognitive learning perspective, in which learning revolves around an individual learner who acquires knowledge, skills, attitudes and competencies. This point of departure is rather common in medical education research, but it has been argued that this field could benefit from exploring and theorising about learning using different 'frameworks' or 
'lenses' (Bleakley 2006; Bordage 2009; Teunissen 2010). Bleakley (2006), for example, argues that socio-cultural learning perspectives are powerful frameworks for exploring, explaining and predicting how medical students learn during clerkships, since they are able to incorporate the complexity and instability of these learning contexts (Bleakley 2006).

Socio-cultural learning perspectives contrast with cognitive theories by relying on (at least) a two-way relationship between individual learning and culture. "Socio-cultural theory treats knowledge as dependent on the knower and the cultural conditions under which it is developed and applied" (Mann et al. 2010). In other words, what and how medical students learn during clerkships depends on the nature of their (interactive) experiences and activities and the meaning that they, and others, attach to these experiences. Lave and Wenger (1991) have articulated the two-way relationship, from their socio-cultural perspective on learning, as the concept of "legitimate peripheral participation in communities of practice", in which a community is a culture-a social structure in which relationships with other people or other communities play an important role. The community determines conditions for learning. Through increased participation newcomers move from the periphery towards the core of a community. In this, social practice is the main phenomenon, with learning - conceptualised as a cognitive process - as one of its integral components. Reaching the centre of a community is not necessarily the main goal of this process. As the main emphasis is on the role of social activity in promoting learning and the formation of the learner's identity, peripheral participation is legitimate in itself (Lave and Wenger 1991). Another socio-cultural perspective on the relationship between mind, culture and context is provided by 'activity theory'. Originating in Vygotsky's work of the early twentieth century, it was further developed by others, including Engeström, whose interpretation is characterised by a focus on 'activity systems' in which learning arises from the interaction between the learner(s) and cultural tools, including the language, physical artefacts and local rules that learners encounter when performing a certain task (Mann et al. 2010; Engeström 1999).

The existing empirical support for the importance of an informal and safe learning environment can be regarded as a fragmented reflection of the picture viewed through a socio-cultural lens. However, this perspective is currently quite rare in medical education research. Since there are empirical and theoretical cues to suggest that a socio-cultural perspective could yield useful insights into learning in general practice, we conducted a study to clarify how medical students learn by participating in general practice and the role of the socio-cultural context therein.

\section{Method}

\section{Theoretical stance}

The methods we used derive partly from our epistemological assumption that when a research topic involves people and their behaviour it is impossible to identify a fully objectifiable truth. It seems more appropriate to speak of multiple truths or realities, which are socially and experientially based and dependent on individuals. By analysing insiders' views we can bring to the surface their experiences and opinions, analyse them and compare them with existing theories. The knowledge resulting from this process is again hypothetical. This theoretical starting point, based on philosophical notions from postpositivism and constructivism, has guided our decision to use a phenomenological approach in our attempt to construct a conceptual framework (Illing 2007). 
Setting

Fifth-year medical students participated in group interviews in week 8 or 9 of the 10 -week general practice clerkship in year 5 of the undergraduate medical programme at Maastricht University. The general practice clerkship is one of twelve obligatory five to ten-week clinical placements spread over years 5 and 6 of the curriculum, which is characterised by problem based learning principles and early patient contacts. During the placement students spend most of their time in a GP surgery and, additionally, groups of ten students meet every week with a tutor to reflect on their experiences and expand their biomedical knowledge.

\section{Sampling and ethical procedures}

We emailed or telephoned the tutors to ask them to permit students to voluntary participate in an interview on a tutorial day. All tutors agreed and informed the students of the study. Prior to the actual group interview, the participating students signed an informed consent form after $\mathrm{JZ}$ had explained to them the procedure and purpose of the interview and the member checking procedure. JZ made it clear to the students that they were free to refuse to answer any question that made them feel uncomfortable and that there were no 'right' or 'wrong' answers to the interview questions. The students received a 15 euro gift voucher for their participation. The researchers had no involvement in the organisation and assessment of the general practice clerkship. Further ethical procedures are not required and therefore not available for this type of research in the Netherlands.

\section{Group interviews}

We developed an interview guide to structure the interviews. First, the students introduced themselves, described the general practice where they were placed and reflected on their experiences. Next, they were asked what and how they had learned so far, specifically what had contributed to or hindered their learning experiences. Later, unless the topic was brought up by the group, questions were asked about the nature of the students' participation, their position and role in the practice and how these elements influenced their learning experiences. During the session, the moderator (CV or AS) sought confirmation and clarification of identified issues by paraphrasing or questioning. JZ observed the group interviews, asked additional questions and, assisted by a minutes' secretary during the last three interviews, took notes on the order of speakers and relevant nonverbal behaviour. Each of the seven sessions was audio taped and transcribed verbatim by externally contracted personnel.

\section{Analysis procedure}

Debriefing sessions of the research team marked the start of the analytical process. The original transcripts were summarised by JZ and submitted to the participants with the request to comment on whether the discussion was rendered accurately and completely (member checking). Computer software Atlas.ti 6 was used to code and analyse the data. After open coding of the first transcript by JZ to identify key phenomena in students' learning experiences and after testing of the code list by PZ, the two researchers reached a consensus on the coding through discussion. This procedure was repeated for the second, third, and fourth transcripts. If deemed necessary, new codes were added or codes were changed. AS read the third transcript and commented on the meaning and application of 
the codes to ensure congruence between the coding and the group interview. After that, PZ and $\mathrm{JZ}$ grouped the codes from the first four interviews into themes to arrive at a preliminary conceptual model. JZ then started a cycle of axial coding for the fifth, sixth and seventh transcripts in order to inductively identify relationships between the themes. JZ and $\mathrm{PZ}$ discussed the resulting codes iteratively, which led to further development and refinement of the conceptual model. During the analytical process JZ kept a diary in which she reported and reflected upon the origins of thoughts and decisions regarding the analytical procedure and outcomes. The diary was discussed frequently by all the researchers.

\section{Results}

A total of 44 students participated in seven group interviews, lasting between 97 and 114 min. The number of participants varied from 5 to 8 , the mean age of the participants was 24 years (range 22-39) and $82 \%$ was female. All the participants had completed at least five clerkships prior to the general practice clerkship, with an average of 10 clerkships. During the interviews, it became clear that the students were used to talking about learning experiences in terms of knowledge, skills and attitudes, but many appreciated being invited to talk about other aspects. Moreover, students often used their hospital experiences as frame of reference in reflecting on their general practice experiences. They expressed the quality of their experiences more often in terms of "fun" and "appreciation" than in terms of "instructive". Nineteen students responded in the member checking procedure and four students made minor remarks, for example regarding details of the GP surgery or their personal take on a certain topic. In the following paragraphs we present the results of the analysis with illustrative quotes.

\section{Developmental space}

The students said they learned by doing. The fruitful effect of 'doing' (such as conducting a consultation relatively independently) depended on the amount of space students experienced to mind their professional development. The 'available space' that emerged from our data consisted of interconnected components and processes contributing to personal growth. Personal growth transcends the acquisition and application of knowledge, skills and attitudes required for a specific clerkship or by a specific physician, and relates to the development of a student's professional identity. We use the term 'developmental space' to denote the explicit and implicit opportunities for identity development that is afforded to and created by students. This term captures students' experiences as participating professionals, which some students summarised as "finally feeling what it's like to be a doctor", or "no longer feeling like a clerk".

P7.6: Sometimes I even feel that it's alright for me to just call and say: well, this patient presents with these complaints, I find this and that on physical examination and er, I am thinking of prescribing this. And then he [the GP] says, it's okay, just write the prescription. So, er yes, this feels very good, because I finally begin to sense something like (...) you are finally beginning to do things yourself.

P5.1: In other clerkships I often see more growth in knowledge and for the rest you just do as you are taught. But here [in general practice] you are also looking at things more critically like... is this really how I want to work (...)? Or how patients accept it, so to say? 
In the following paragraphs we first describe two components of developmental space: contextual space and socio-emotional space. We then describe, in terms of these different types of spaces, three groups of activities that we identified as central to the general practice clerkship: holding independent consultations, talking about consultations, and observing the GP. These so called participatory activities demonstrate students' potential for growth through the concept of developmental space.

\section{Contextual space}

The possibility for students to mind their learning was influenced by the attributes of the working environment, such as material, organisational and educational elements. Contextual space, for example, was strongly determined by the presence or absence of a special room for students with a computer and access to patient records and by the scheduling of patient consultations for students. The organisational element is manifest in clerkship length, specialty, and its position within the curriculum. For example, prior (clerkship) learning expectations and experiences influenced students' perceptions of the contextual space as was exemplified by students expressing the contrast with hospital clerkships as "being offered a lot more opportunities to learn". Contextual space was also determined by the time available for supervision, mutual observation and feedback, and the patient mix seen by students. These elements were potential educational stimuli for students.

P3.3: I do not have my own surgery hour, but the way we do it is that we always look in the computer and then there are usually two patients in the waiting room and then he [the GP] says well which one would you like to take? Do you want the knee problem or the lung follow-up? And then I pick the one I can learn from the most.

\section{Socio-emotional space}

Socio-emotional space embodies how students' state of mind, often originating from interactions with the social environment, influences possibilities for learning. Students' relationships with their supervisor, other team members and patients influenced their social and professional position within the practice. The nature of these relationships was partly influenced by the local working climate and habits, partly by a personal 'click' with the supervisor and other personnel, and was further developed by participation in patient care. The strong impact of the student's position was manifest in its effect on emotional outcomes such as enjoyment and feeling respected and confident. These positive emotions enabled learning by providing space for students to build their skills and experiences, to accept weaknesses and to feel free to ask questions. If these elements were unclear or disturbing, students were compelled to attend to these negative aspects and as a result effective use of the socio-emotional space would be impaired.

P5.5: You have to be on your toes all the time [in the hospital]. I mean, with the GP I felt this was yes... much less so. That was good, for then you start to feel that you are not afraid to ask questions and also that you can say, well, I don't know this, tell me some more about it, while if you say that in the hospital you always feel like... yes, I should really know that. And then they say like: alright, go and look it up in the textbooks. (...)

P5.3: Or you get the whole lecture like... Do you really not know that?!

P7.4: And when the atmosphere is not good (...) then you hold back. (...) 
P7.6: Then you really always have to adjust to what a doctor expects and wants from you. And because of that you cannot really be yourself, for you have, you lose some self confidence anyway and then you, yes, you have to take a different attitude every time and...

P7.5: That takes energy.

P7.6: That takes an awful lot of energy.

Participatory activities

We will describe three types of participatory activities which embody the meaning of and interaction between contextual space and socio-emotional space. This approach allows us to elucidate how 'learning by doing' contributes to students' personal development.

\section{Independent consultations}

The students' main activity was patient contacts. After an introductory period varying from $1 \mathrm{~h}$ to several days, students became increasingly independent in taking a history, doing a physical examination, and making a management plan. The GPs had the final responsibility and used varying strategies to ensure patient safety. Further supervisory activities were partly formal (weekly observation-based evaluations) and partly depended on GPs' routine approaches and students' development over time. How students learned to become progressively more independent in conducting consultations and how these learning experiences contributed to the development of their professional identity can be explained when we study these processes through the lenses of contextual and socio-emotional spaces.

\section{Contextual space}

Clerkship length and the type of primary care tasks in general practice gave students ample opportunity to engage in patient encounters and see patients again at follow-up visits. This ability to engage in continuity of care gave students essential feedback on their medical decision making and enabled them to build doctor-patient relationships. The specific illnesses and complaints in primary health care stimulated students to develop a 'new way of thinking and acting', which they found both inspiring and instructive.

P3.2: In the hospital we are used to, when people come, that means something is wrong. (...) And especially in general practice you make that distinction. (...)

P3.4: And what to me is especially good, (...) they [GPs] allow you to say, like what would you do? And then you have to think for yourself. I think this should be referred, or not, or... and I think in this way you learn somehow. For when he just says, yes I'll refer, then you think, oh yes, of course. But you haven't really thought it through for yourself.

Having their own consultation room gave students a clear status and enabled them to further develop their independence. This room symbolised their position within the practice and supplied them with a safe, private space. The same applied for having access to a computer and a well organised and filled consultation schedule. The latter often developed over time, and was a sign of growth.

P2.3: Your own room that is really very important, isn't it? (...) You feel much more at home, much more at ease, much more... it seems silly, but you feel much more respected when you can sit in your own room... 
Which aspects provided valuable guidance and feedback to students depended on their stage of development. At first, GPs' observations, feedback and explanations were the main stimuli, but later on students learned more from being confronted with the consequences of their own actions, which was more powerful than merely being told what they had or had not done well.

P5.1: Generally I have been able to see quite a few patients again at the following visit, and I have really learned a lot from that. (...) Things like that are just good for you, to receive feedback on what you have done. Not only er, as an opinion or as yes... as feedback from some GP, but just like... yes objective things: lab results, X-ray results, er... improvement of the complaints or indeed worsening.

If, in time, the GP remained observing the student's consultations with patients, this considerably dampened the experienced instructiveness of this activity because it detracted from the student's opportunities for self-development. Nevertheless, during the whole clerkship it remained crucial that the GP was available to answer questions or take part in the consultation, both for the sake of patient safety and learning.

P6.4: Mostly I see a lot of patients together with my GP because there aren't that many. In itself that is very good, because he can give feedback immediately. (...) But on the other hand, it sometimes makes me feel uncertain because the GP is present and (...) then you sort of feel someone breathing down your neck, like how would he do this, and that inhibits you from speaking freely.

\section{Socio-emotional space}

As a result of the one-to-one relationship with their supervisor, students felt there was room for the GP to monitor their development, to increasingly trust them as professionals and to give them progressively more independence in patient consultations. The same development of trust, albeit with a less pronounced impact, took place in the students' relationships with other staff, such as receptionists and nurses. Independent patient consultations were significant in light of students' social position in the practice, which varied from being an accepted member of the team that contributes to patient care to being 'just the clerk/intern'. Providing continuity of care for a group of patients and establishing relationships with them contributed to the students feeling part of the team and created a firm basis for trying out new tasks or skills. The sense of being appreciated and being responsible resulting from feeling recognised as a team member was a strong motivator for students and strengthened their confidence. Moreover, taking responsibility increased students' awareness of their own strengths and weaknesses thereby guiding them in when and how to ask for supervision or read up on a certain topic.

P7.5: Well, what I also like very much during this clerkship is that you are not so much seen as the clerk who is a nuisance and in the way. (...) You really have your own place there. You see patients, you feel you are really useful. (...) And because of that, you are more, simply part of the team and not someone placed below it.

The specific so-called minor illnesses and complaints which students 'mastered' in general practice contributed to their sense of professional identity as they became increasingly competent to answer the various questions patients asked them. Moreover, students also experienced personal growth as they became better able to deal with medical problems in their private life, for example when family members asked questions about their health. 
Conversations about patient consultations

Student-patient encounters were framed in conversations with the GP during or after the consultations. These offered opportunities to both students and GPs. Together they could discuss patient management and elaborate on medical and behavioural issues, while the student could ask questions and the GP could provide feedback on student performance. Initially, these conversations would centre on practical feedback and on exploring and setting boundaries of independence based on the student's performance and the GP's customary approach. In time, once student and GP had established a feasible and safe working mode, students could develop a certain level of independence in deciding to what extent, when and how they wanted to contact their supervisor. Talking about patients was associated with the development of self-confidence, professionalism and medical knowledge.

\section{Contextual space}

The combination of clerkship length and one-to-one supervision offered a firm basis for providing, valuing and using appropriate feedback. Moreover, it provided room for the student to change and for the supervisor to notice that change. In most cases, students could consult the GP at any time, and transparency regarding how they could approach the GP reassured students.

P7.5: My room is next to the GP's room. And er, we have arranged that when I am finished with a patient I leave the door ajar, and when he is finished with his patient and he sees my door is open he comes in. He sits down and then he says: well, tell me, er, what do we have here? And what are you going to do about it?

Whether or not the patient was present during a conversation between the GP and the student influenced if and how students asked questions or expressed doubt, since students thought this could interfere with the professional relationship they were trying to build with a patient. Knowledge and experiences obtained during previous clerkships made it easier for students to contribute to medical discussions and to value received feedback. Supervisors promoted fruitful discussions when they stimulated students' thought processes in a challenging and non-judgemental manner, when they gave them a role in patient care and when they explained things when necessary.

P5.1: Especially with complaints of fatigue, yes, I often would think somatically, while yes... my supervisor's experience naturally had taught that it is often not somatic. (...) And one time he said well, do you know what we'll do? When you think it is somatic (...) then we'll just do a blood test, you will see the patient again after a week and then you can see if you can find something... and I have never found anything.

\section{Socio-emotional space}

Students reported that the relatively friendly atmosphere and general interest that surrounded and coloured the conversations created room for them to ask questions and show weaknesses. Patient related conversations were most appreciated when student and supervisor were more or less equal conversation partners. Equality was apparent from the GP's attitude and language and from the contribution the student was allowed to make to 
the diagnosis or treatment plan. This made students feel they were taken seriously and challenged them to be a really equal conversation partner and take responsibility. Students also derived a sense of equality from conversations when the GP showed that he/she was not omniscient. Interactions with receptionists and/or nurses who showed they regarded the student as a professional could foster a similar sense of professionalism.

P1.1: Or also when the GP doesn't know something, or when he has the lab results then... At least with me they very often asked like well, what do you think? What would you do? Would you refer him or? Yes, I always liked that (...) and that way I felt they were taking me seriously.

\section{Observing the general practitioner}

Students observed their supervisors during patient consultations, in the running of the practice, in communicating with colleagues and in balancing their professional and private lives. Planned observations of patient encounters occurred mostly early in the clerkship and the extent of this activity depended on the level of independence the GP granted the student. In time, observations generally became context-related or occurred only when requested. The observations provided students with information about primary health care in general and with examples of how the GP fulfilled his/her tasks. In group practices, several GPs instead of one offered role models.

P6.1: I learn from the way my GP handles things, (...) how she deals with patients, how she deals with colleagues, how she deals with certain conditions, whether or not you should treat them, whether or not you should refer (...) Just a role model of someone with a lot of experience.

\section{Contextual space}

Clerkship length provided students with enough time to understand and value their observations of GPs' behaviour, preventing them from passing early judgements and deepening their understanding of certain behaviour or idiosyncrasies. Students were used to view and judge primary care from a secondary care perspective. By observing how a GP communicated with colleagues in secondary care, students got the full picture and this was an important insight to guide them in their future professional practice. General practices were often located adjacent to or near the GP's home and this gave students the opportunity to observe their GP in his/her private life and how this interacted with their professional identity. Sometimes these observations as well as conversations with the GP on this topic, prompted students to reflect on their future professional life in a different and more intense way than they had done during hospital based experiences.

P2.2: Now I see much more of the GP's life style so to speak. And maybe I have just never thought about it so much.

P2.6: You often disconnect it. (...)

P2.2: During my clerkships (in the hospital) I did not really see this and now you do see it and that is another extra dimension that makes you think about what you want.

Variation in role models was very much appreciated. It made students feel they could develop their own style and use those elements they considered worthwhile. Moreover, variation in observations made students aware of how differences in working style affected patient encounters. 
P3.3: Because I could observe two doctors, and one is really like, (...) he is really very open you know, there isn't much distance. And the other is somehow, yes he is, he is more businesslike, more aloof. (...) And then you see, well yes, how I would want to be in the future (...) for you also see how patients respond, and also how you can get the most out of a conversation.

Observation in an instructional context, when a part task, such as a communication technique or knee examination, was demonstrated, was considered powerful when it was embedded in students' authentic experiences or in questions derived from these experiences. Students learned the most when they could perform the observed task immediately afterwards.

\section{Socio-emotional space}

Especially early in the clerkship, observation enabled students to learn more about their supervising GP as a professional and as an individual. Some students said they partly adapted their own working style to that of their supervisor to make a good impression and, they hoped, to promote being accepted as a professional, even though they felt that this did not directly contribute to their own development. Comparing what they observed with their own views and behaviours could lead to both positive and negative identification. Students spoke of a need to have a positive role model. If they could identify with a GP, they sometimes interpreted this as confirmation of their own professional identity, and this provided room for further development. Negative identification could reinforce students' own ideas about professionalism, but it could also make them feel insecure or uncomfortable if they were unable to do something about situations they considered undesirable.

P3.5: My GP is really someone who says, it is obviously not this, not, not. But patients just hear a jumble of a lot of terms and finally he says what it is. And I think; you see those people looking very anxious at first and then things just go horribly wrong (...) Then I just prefer to do things myself, rather than sitting there.

When GPs made themselves vulnerable, by being very open about their reflections on their feelings during patient encounters, for example, or by admitting to patients that they did not know it all, they set an example for students, who would then feel free to adopt similar behaviour.

P2.6: Then you see how he does it, how at the end of the patient contact he stops to think: Well, what has this done with me, and he tells you about it too. Even if it is quite... well quite deep and... that he makes himself vulnerable. And when he is not afraid to... then I will also not be afraid.

\section{Discussion}

\section{Principal findings}

Our study was aimed at clarifying how medical students learn from participating in a general practice setting by exploring the socio-cultural context of the learning environment. Our analysis revealed that students need developmental space in order to be truly 
mindful of their learning processes. Both contextual and socio-emotional elements influenced the way opportunities for developing a professional identity were afforded to or created by students. We explained these elements by showing their effects in relation to three 'participatory activities': independent consultations, conversations about consultations, and observation of GPs. Pivotal in these activities was the meaning attached to the student's role and how that was reflected in and connected with their level of independence, with being 'allowed' to be a learner and with the freedom 'to really be a doctor'. The nature of the social and professional interaction with the supervising GP (and others such as patients and receptionists) and the physical and organisational environment had a direct or indirect impact on how students experienced their role and transition herein. Furthermore, these components and processes influenced how students came to feel motivated, respected and self-confident, which were emotional prerequisites for the creation of developmental space and the ensuing opportunities for personal growth.

\section{Relationship to other studies}

Our findings are in line with empirical evidence concerning medical students' learning processes in the workplace, showing the importance of elements like the role of supervisors, a safe learning environment and the development of students' confidence. We think our study contributes to the existing knowledge by adding insights that can promote our understanding of why and how those elements influence student learning. We will explain this by interpreting our results in the light of findings from earlier empirical and theoretical studies.

Dornan et al. (2007) developed an experience-based learning (ExBL) model, which partly aligns with our findings. It links processes and outcomes of workplace learning during medical students' mainly hospital based learning experiences. Central in this model is the concept of supported participation, which is conducive to learning outcomes, such as a positive state of mind and practical competence, which, in turn, influence student learning (Dornan et al. 2007). Although the components and detailed descriptions of the ExBL model show many similarities with our findings, from a conceptual point of view, our approach differs in the central position we accord to developmental space rather than supported participation. As a result of this focus on the contextual and socio-emotional implications of participatory activities and their impact on student learning, our results suggest ways to explain why and how the processes of supported participation that are at the core of the ExBL model affect student learning in the workplace.

When we compare our results regarding the relationship between participatory activities and learning with Teunissen's, postgraduate based, framework of workplace learning (Teunissen 2008), we find that this framework resonates with our findings, because it recognises the importance of integration of social, cultural and material context. However, it is different in its emphasis on individual cognitive learning processes, reflecting aspects of Eraut's theory of informal learning (Eraut 2004), which postulates that learning processes are structured by conscious and unconscious thoughts regarding personal attributes (individual beliefs, values, goals, memories and knowledge structures) and personal experiences (individuals' perceptions of a specific situation).

Our concept of developmental space also resonates with Vygotsky's (1978) claim that "an essential feature of learning is that it creates the zone of proximal development", i.e. the distance between learners' actual developmental level and their level of potential development. This dynamic distance is both determined and bridged by social interaction 
(Vygotsky 1978). Our findings illustrate how the combination of contextual elements and interactive processes between GPs and students can create situations in which students appear to make a transition through their zone of proximal development. One might say that developmental space is like the water and sunshine that are essential for Vygotsky's 'buds' and 'flowers' to turn into 'fruits' of development (Vygotsky 1978). From this point of view, the concept of developmental space is also in alignment with Maslow's hierarchy of human needs. This humanist orientation towards learning relies on the premise that physiological and emotional needs have to be met before a person can act upon growth needs that lead towards self-actualisation (Mann et al. 2010).

Our findings with respect to the relationship between socio-emotional and contextual elements and potentially constructive participatory activities also resemble aspects of cultural-historical activity theory (CHAT), which underlines the relationship between learners' actual 'doing' and the meaning assigned to actions through the historically determined rules, roles and artefacts of the community in which the learner acts (Engeström 1999). This theory shows similarities to our findings in that it provides an analytical framework, including contextual and cultural mediators that can identify components of a learning environment that either hinder or promote learning through participating in activities. It differs from our findings in that it directly attributes a specific outcome to an action, while our focus is the process of arriving at a favourable situation, in which a student can begin to learn.

Lave and Wenger's (1991) concept of legitimateness is easily recognisable in our findings concerning the importance of feeling accepted and respected both as an individual and as a professional while at the same time being 'allowed' to be a learner. Also, the value students in our study placed on increased involvement in professional practice, reflected in more scheduled patient consultations and involvement in patient management decisions, strongly resembles the notion of learning as in integral component of the movement from the periphery to the centre of a community (Lave and Wenger 1991).

\section{Strengths and limitations}

Our interpretation of learning from the perspective of developmental space is based on rich empirical findings and a clear theoretical perspective. In analysing the data, we have tried to strike a reflective balance between 'allowing the data to speak for itself' and employing a socio-cultural lens. In this way one might regard our findings as providing a bridge between the predominantly cognitive research in this field and social cultural learning perspectives. Both ends of this bridge appear to have strong foundations, while empirical as well as theoretical pillars support the bridge and provide strength to allow safe crossing. The fact that our results are only based on clerkship experiences in general practice could be regarded as a limitation of their applicability in other settings. However, we think that in the preceding paragraphs we have demonstrated how our results show overlap with findings from studies in predominantly hospital based and postgraduate settings. Because the general practice clerkship is scheduled near the end of the curriculum, the participants may have been more aware of the process of professional identity formation, which may have coloured their learning experiences. Nevertheless, the basic principles of our model also resonate in findings among third year medical students regarding early patient contacts (Ashley et al. 2008). We are less sure about the impact of country-related differences with respect to the culture and context of both hospital and general practice based learning settings. 
Unanswered questions and further research

We would recommend further research from a socio-cultural perspective to refine our interpretations and to include other aspects of medical workplace learning. For example, it would be interesting to establish whether similar prerequisite elements and processes would create 'teaching space' for supervisors. Furthermore, we think it would be valuable to investigate what sorts of 'truths' regarding medical students' learning processes hold true for educational developers, and how these relate to our socio-cultural concept of learning. This is of particular importance with respect to the design and implementation of (changes in) clinical placements. Relatively long placements may be eminently suitable to provide essential room to foster students' development by offering opportunities for creating a safe learning environment, establishing a (one-to-one) relationship with a supervisor and a gradual increase in clinical responsibility. Like other practical implications of our research findings, such as students having their own consultation room, these preliminary suggestions should be interpreted with caution and used chiefly to guide further research, considering their obvious dependence on local contexts.

\section{Conclusion}

We clarified medical students' learning processes during clerkships by analysing their experiences from a socio-cultural perspective. Our results reveal why students need developmental space in order to truly 'learn from doing'. We have demonstrated how the concept of developmental space is created through the intertwinement of workplace context, individual and professional interactions, and emotions such as feeling respected and self-confident. These forces frame students' activities and thereby determine how much room is created to enable them to mind their own professional development.

Acknowledgments Firstly we would like to thank the students for sharing their experiences so frankly with us. We thank V. Hanssen, M. Beld and W. van Ommen for transcribing the interviews. Furthermore, T. Dornan has reflected constructively on preliminary findings and M. Gorsira has provided essential feedback on English grammar and style.

Open Access This article is distributed under the terms of the Creative Commons Attribution Noncommercial License which permits any noncommercial use, distribution, and reproduction in any medium, provided the original author(s) and source are credited.

\section{References}

Ashley, P., Rhodes, N., Sari-Kouzel, H., Mukherjee, A., \& Dornan, T. (2008). They've all got to learn. Medical students' learning from patients in ambulatory (outpatient and general practice) consultations. Medical Teacher, 31, e24-e31.

Bleakley, A. (2006). Broadening conceptions of learning in medical education: The message from teamworking. Medical Education, 40, 150-157.

Bordage, G. (2009). Conceptual frameworks to illuminate and magnify. Medical Education, 43, 312-319.

Dornan, T., Littlewood, S., Margolis, S. A., Scherpbier, A., Spencer, J., \& Ypinazar, V. (2006). How can experience in clinical and community settings contribute to early medical education? A BEME systematic review. Medical Teacher, 28, 3-18.

Dornan, T., Boshuizen, H., King, N., \& Scherpbier, A. (2007). Experience-based learning: A model linking the processes and outcomes of medical students' workplace learning. Medical Education, 41, 84-91. 
Engeström, Y. (1999). Activity theory and individual and social transformation. In Y. Engeström, R. Miettinen, \& R. Punamäki (Eds.), Perspectives on actvity theory. Cambridge: Cambridge Universiy Press.

Epstein, R. M., Cole, D. R., Gawinski, B. A., Piotrowski-Lee, S., \& Ruddy, N. B. (1998). How students learn from community-based preceptors. Archives of Family Medicine, 7, 149-154.

Eraut, M. (2004). Informal learning in the workplace. Studies Continuing Education, 26, 247-273.

Fernald, D. H., Staudenmaier, A. C., Tressler, C. J., Main, D. S., O’Brien-Gonzales, A., \& Barley, G. E. (2001). Student perspectives on primary care preceptorships: Enhancing the medical student preceptorship learning environment. Teaching and Learning in Medicine, 13, 13-20.

Gordon, J., Hazlett, C., Ten Cate, O., Mann, K., Kilminster, S., Prince, K., et al. (2000). Strategic planning in medical education: Enhancing the learning environment for students in clinical settings. Medical Education, 34, 841-850.

Illing, J. (2007). Thinking about research: Frameworks, ethics and scholarship. In T. Swanwick (Ed.), ASME Booklet Understanding Medical Education.

Lave, J., \& Wenger, E. (1991). Situated learning: Legitimate peripheral participation. Cambridge: Cambridge University Press.

Mann, K., Teunissen, P. W., \& Dornan, T. (2010). Perspectives on learning. In T. Dornan, K. Mann, A. Scherpbier, \& J. Spencer (Eds.), Medical education. Theory and practice. Churchill: Edinburgh.

Murray, E., Jolly, B., \& Modell, M. (1999). A comparison of the educational opportunities on junior medical attachments in general practice and in a teaching hospital: A questionnaire survey. Medical Education, $33,170-176$.

O'Sullivan, M., Martin, J., \& Murray, E. (2000). Students' perceptions of the relative advantages and disadvantages of community-based and hospital-based teaching: A qualitative study. Medical Education, 34, 648-655.

Pearson, D. J., \& Mckinley, R. K. (2010). Why tomorrow's doctors need primary care today. Journal of the Royal Society of Medicine, 103, 9-13.

Silverstone, Z., Whitehouse, C., Willis, S., Mcardle, P., Jones, A., \& O’Neill, P. A. (2001). Students' conceptual model of a good community attachment. Medical Education, 35, 946-956.

Svenberg, K. (2007). A memorable consultation: Writing reflective accounts articulates students' learning in general practice. Scandinavian Journal of Primary Health Care, 25, 75-79.

Teunissen, P. W. (2008). Unravelling learning by doing. Amsterdam: Vrije Universiteit Amsterdam.

Teunissen, P. W. (2010). On the transfer of theory to the practice of research and education. Medical Education, 44, 534-535.

Thistlethwaite, J. E., \& Jordan, J. J. (1999). Patient-centred consultations: A comparison of student experience and understanding in two clinical environments. Medical Education, 33, 678-685.

Vygotsky, L. S. (1978). Mind in society. The development of higher psychological processes. Cambridge, Massachusetts: Harvard University Press.

van der Zwet, J., Hanssen, V. G., Zwietering, P. J., Muijtjens, P. J., van der Vleuten, A. M., Metsemakers, C. P., et al. (2010). Workplace learning in general practice: Supervision, patient mix and independence emerge from the black box once again. Medical Teacher, 32, e294-e299. 